\title{
Coupled Inductor and Voltage Doubler Circuit for High Step-Up DC-DC Converter
}

\author{
Mr. Abhinav V. Deshpande \\ Internal Full Time (IFT) Ph.D. Research Scholar \\ School of Electronics Engineering (SENSE) \\ Vellore Institute of Technology (VIT), Vellore, Tamil Nadu, India-632014 \\ avd.a.deshpande@gmail.com
}

\begin{abstract}
:
In this research paper, a novel high step up dc-dc converter with a coupled inductor and voltage doubler circuits is proposed. The converter achieves a high step up voltage gain with an appropriate duty ratio and low voltage stress on the power switches. Also, the energy which is stored in the leakage inductor of the coupled inductor can be recycled to the output. The operating principles and the steady state analysis of the proposed converter are discussed in detail. Finally, a prototype circuit of the proposed converter is implemented in the laboratory in order to verify the performance of the proposed converter.
\end{abstract}

Keywords: Step Up Voltage Gain, Coupled Inductor, Voltage Doubler

\section{Introduction:}

A DC-DC converter converts directly from dc to dc and is simply known as a DC converter. A dc converter can be considered as dc equivalent to an ac transformer with a continuously variable turns ratio. Like a transformer, it can be used to step down or step up a dc voltage source. The DC converters are widely used for the traction motor control in the electric automobiles, trolley cars, marine hoists and mine haulers. They provide a smooth acceleration control, high efficiency and a fast dynamic response. The dc converters can be used in the regenerative braking of the dc motors in order to return the energy back into the supply and this feature results in the energy savings for the purpose of transportation systems with frequent stops. The dc converters are used in the dc voltage regulators in order to generate a dc current source, especially for the current source inverter. A boost converter is generally used and it has several advantages such as the simple structure, continuous input current and clamped switch voltage stress to the output voltage. However, it is very difficult to satisfy both the high voltage conversion ratio and the high efficiency at once. This is primarily due to the parasitic resistances, which cause a serious degradation in the step-up ratio and the efficiency as the operating duty increases. Moreover, in a high output voltage applications, a high voltage rating diode causes a severe reverse recovery problem and it requires a snubber. As a result, a general boost converter would not be acceptable for high step-up applications. In order to overcome this limitation, various types of step-up converters, utilizing the voltage conversion ability of a transformer, can be adopted. In order to provide such a large step-up/step-down voltage gain, the non isolation converters would have to work with the extreme duty ratios, in the case of boost type converters, a large duty ratio would be necessary, but this is not possible due to the latch up condition. Moreover, the short conduction time of the rectifier switch determines a short pulse current with a high amplitude flowing through it, and thus a severe rectifier reverse recovery problem.

\subsection{Available Solutions to the Above Problems Includes:}


[1] The transformer-based converters (as fly back, forward) the transformer being an element that introduces many losses and the switch being submitted to a high voltage stress (double the input voltage).

[2] A cascade of two boost converters, with its two energy processing steps, and the two sets of active switches, magnetic components and the controllers that have to be synchronized in order to avoid the beat frequency.

[3] The quadratic boost or buck converters, also presenting a too much complexity.

[4] A much phase and phase shift buck converters as the voltage regulator modules (VRM's).

[5] Transformer less hybrid converters which are based on a defined switched capacitor/switched inductor cell and hard switching basic converters with inserted switched capacitor structures, the last two solutions (d, e) still presenting a limited DC gain.

A new parameter for increasing the DC ratio in step-up and step-down converters was introduced by the use of the tapped inductor; a tapped inductor replaces the output filter inductor in a buck converter. A coupled inductor is used in a boost or buck-boost converter instead of the input inductor. The choice of the turns ratio $\mathrm{N}$ of the coupled inductor allows for an additionally decreasing/increasing the DC gain. The dc-dc fly back converter is adopted in order to achieve a high step up voltage gain by adjusting the turns ratio of the transformer. This converter has the merits of a simple topology, easy control and low cost but the fact that the leakage inductor energy of the transformer cannot be recycled results in a low efficiency and high voltage stress on the active switch. In order to reduce the voltage stress, an RCD snubber is used. However, this decreases the efficiency. The transformer less dc-dc converters include the cascade boost type, the quadratic boost type the switched inductor type, the voltage lift type, the voltage doubler type, the capacitor diode voltage multiplier type and the boost type that is integrated by using a switched capacitor technique. These converters can provide a higher voltage gain than the conventional dc-dc boost converter. However, the voltage gain of these converters is only moderately high if a higher voltage gain is required, these converters must cascade more power stages, which will result in low efficiency. A conventional high step up dc-dc converter with a coupled inductor technique is shown in Figure 1. The structure of this converter is very simple, and the leakage inductor energy of the coupled inductor can be recycled to the output. However, the voltage stresses on the switch S1 and diode D1, which are equal to the output voltage, are high. This research paper presents a novel high stepup dc-dc converter which is as shown in Figure 2. The coupled inductor and the voltage doubler techniques are integrated in the proposed converter in order to achieve a high step-up voltage gain. 


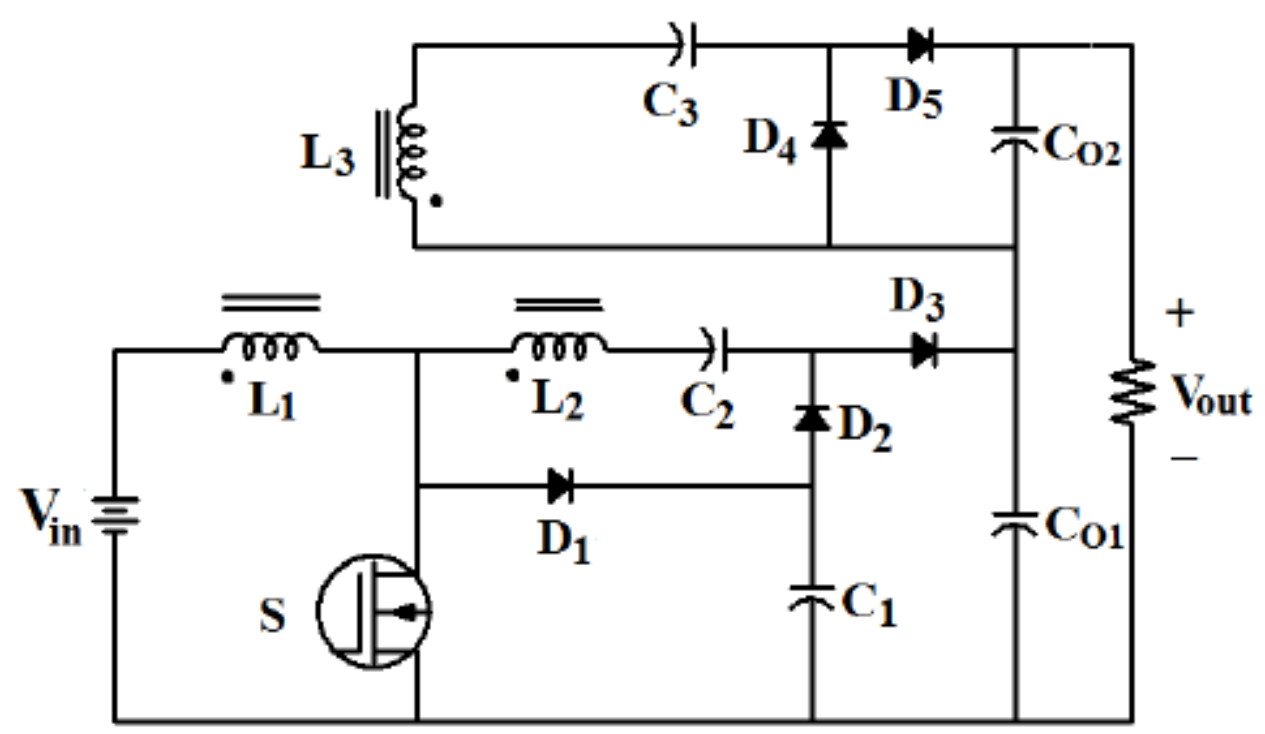

Figure 1 Circuit Configuration of the Conventional High Step up DC DC Converter

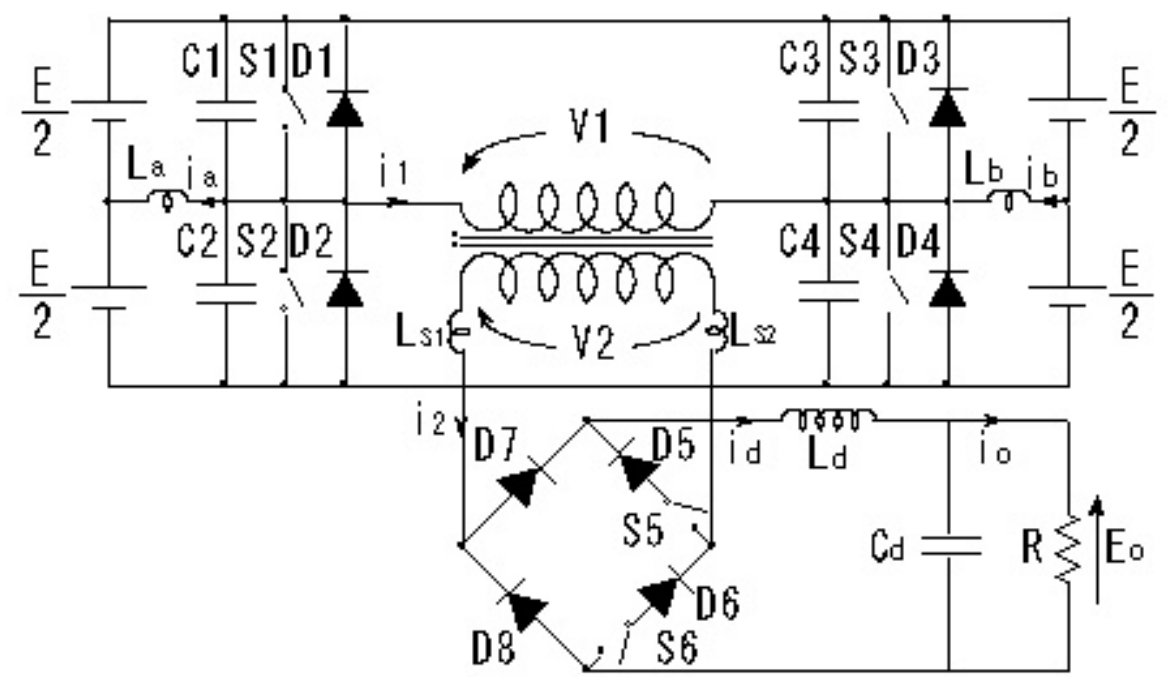

Figure 2 Circuit Configuration of the Proposed Converter

\section{Operating Principle of the Proposed Converter:}

Figure 2 shows the circuit configuration of the proposed converter, which consists of two active switches $\mathrm{S} 1$, and S2, one coupled inductor, four diodes D1-D4, and two output capacitors C1 and C2. The simplified circuit model of the proposed converter is shown in Figure 3. 


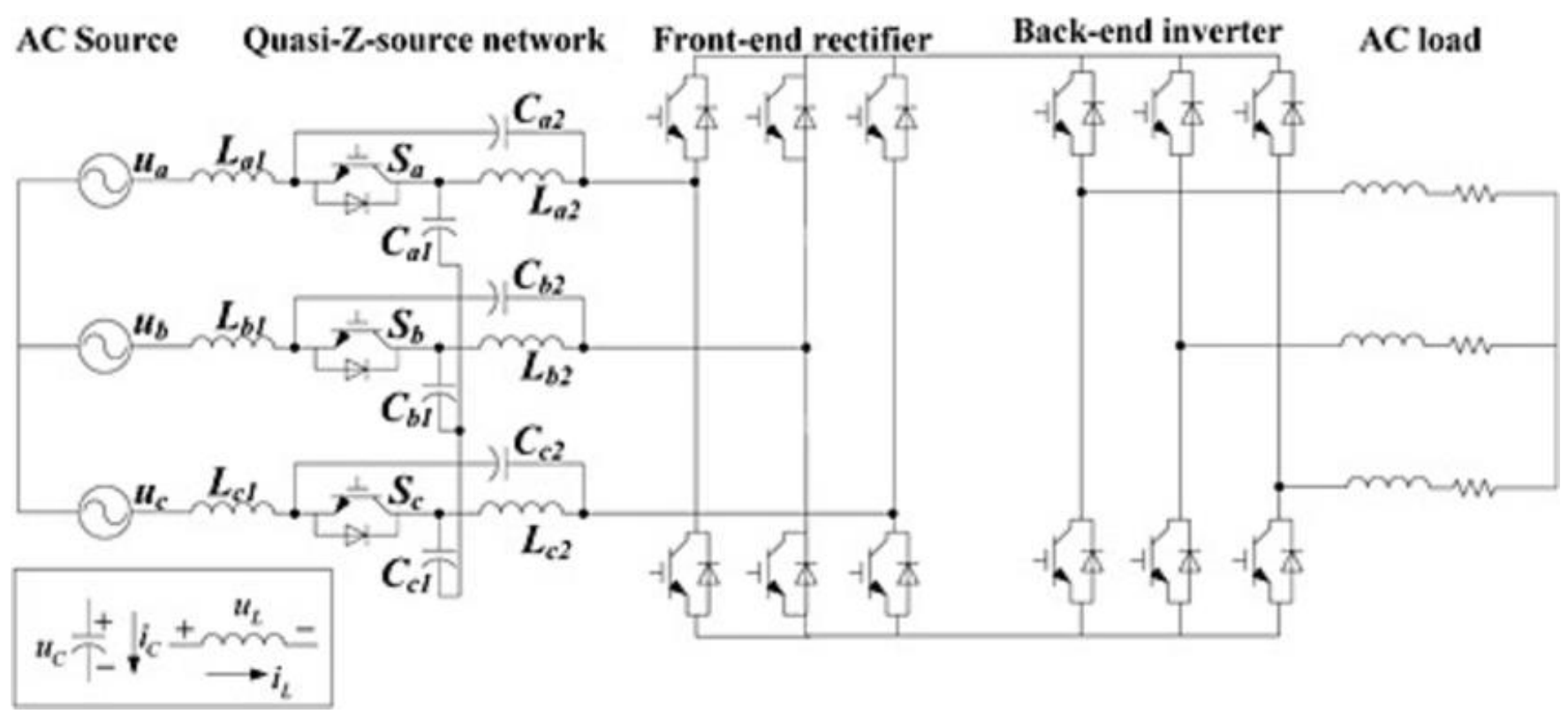

Figure 3 Simplified Model of the Proposed Converter

The coupled inductor is modeled as a magnetizing inductor Lm, a primary leakage inductor Lk1, a secondary leakage inductor Lk2 and an ideal transformer. The capacitors CS1 and CS2 are the parasitic capacitors of S1 and S2 respectively. In order to simplify the circuit analysis of the proposed converter, some conditions are assumed as follows: First all the components are ideal. The ON state resistance RDS (ON) of the active switches, the forward voltage drop of the diodes, and the ESR of the coupled inductor and the output capacitors are ignored. Second, the output capacitors C1 and C2 are sufficiently large and the voltages across $\mathrm{C} 1$ and $\mathrm{C} 2$ are considered to be constant during one switching period.

\section{Modes of Operation:}

\subsection{Mode $1[\mathrm{t} 0, \mathrm{t} 1]$ :}

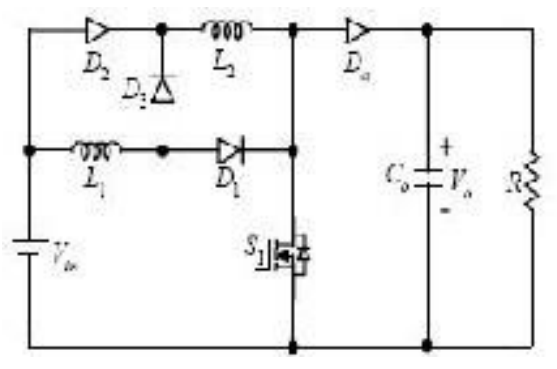

\section{Figure 4 Mode 1}

At $t=t 0, S 1$ and $S 2$ are turned on. The current flow path is shown in Figure (a). The DC source energy is transferred to Lm and Lk1 trough D3, S1 and S2 so the currents iLm, iLk1 and iD3 are increased. The energy which is stored in Lk2 is released to Lm and Lk1 through D4, S1 and S2. Thus, iLk2 is decreased. Meanwhile, the energy which is stored in Lk2 is recycled. The energy which is stored in CS2 is rapidly and completely discharged. The energies which are stored in $\mathrm{C} 1$ and $\mathrm{C} 2$ are discharged to the load. This mode ends when iLk2 is equal to zero at $\mathrm{t}=\mathrm{t} 1$. 
3.2. Mode $2[\mathbf{t} 1, \mathrm{t} 2]$ :

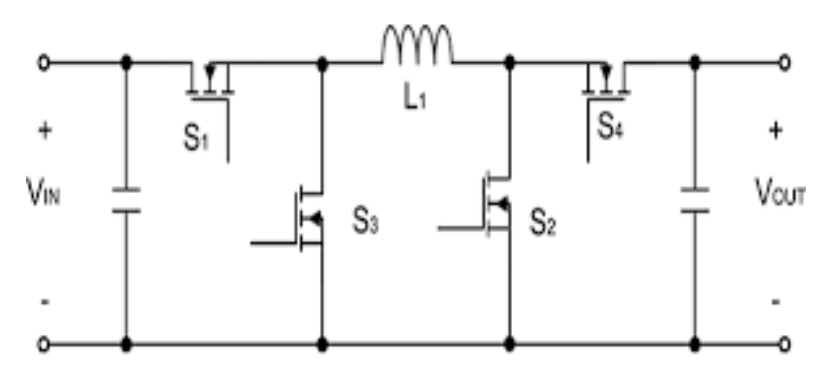

Figure 5 Mode 2

In this mode, S1 and S2 are still turned on. The current flow path is shown in Figure (b). The DC source energy is still transferred to Lm and Lk1. Thus, iLm and iLk1 are still decreased. The energies which are stored in $\mathrm{C} 1$ and $\mathrm{C} 2$ are still discharged to the load.

\subsection{Mode $3[t 2, t 3]$ :}

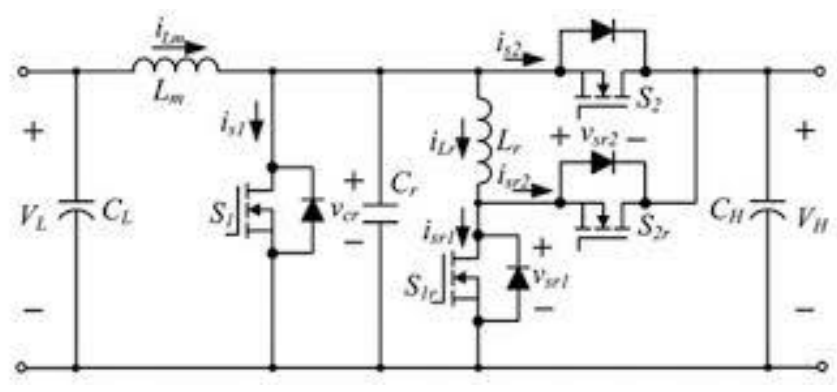

Figure 6 Mode 3

At $t=t 2, S 1$ is turned off and S2 is still turned on. The current flow path is shown in Figure C. The DC source energy is still transferred to Lm, Lk1 and CS1. Meanwhile, the voltage across S1 is increased rapidly. The energies which are stored in $\mathrm{C} 1$ and $\mathrm{C} 2$ are still discharged to the load. 
3.4. Mode 4 [t3, t4]:

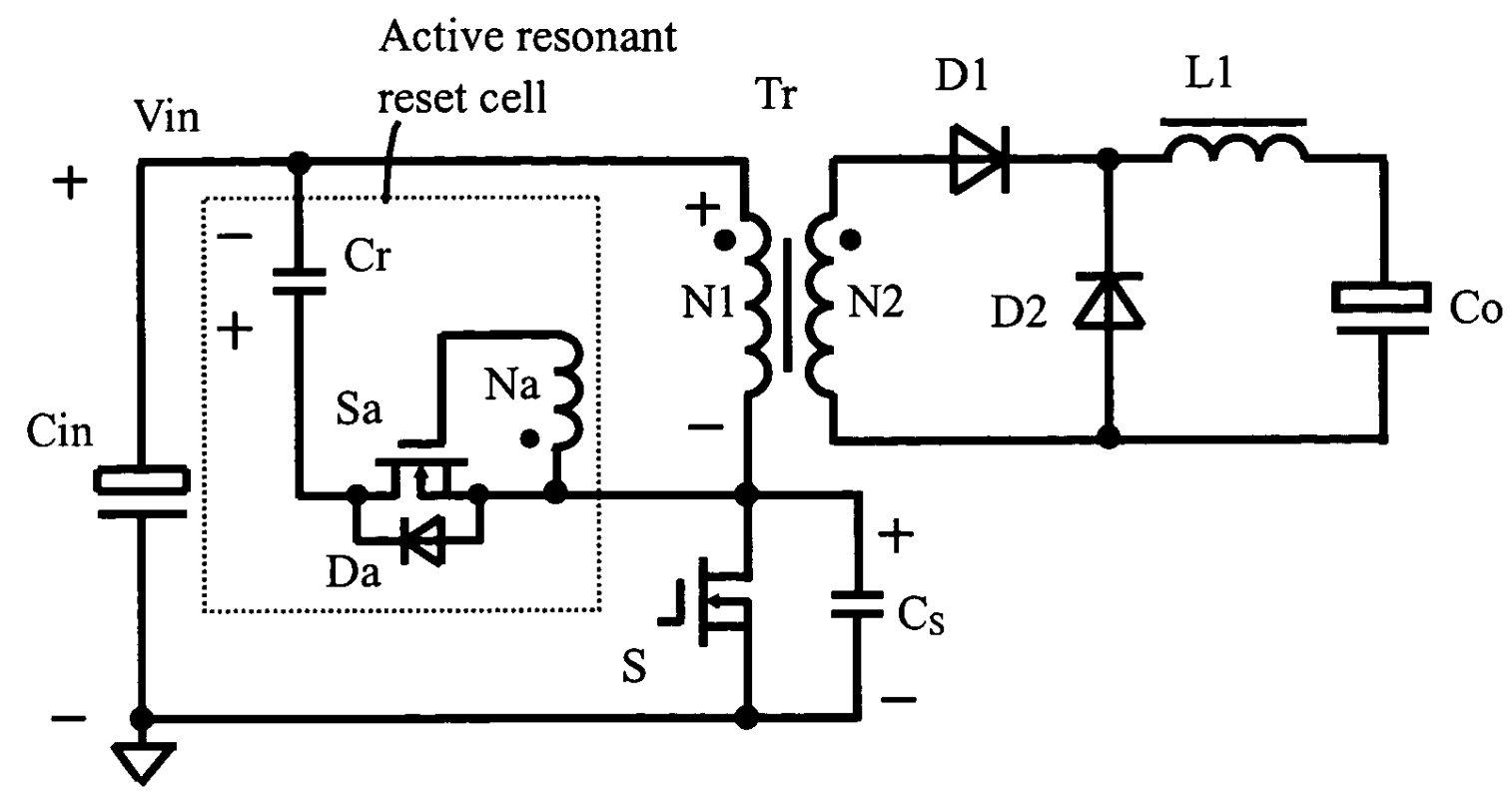

Figure 7 Mode 4

During this time interval, S1 is still turned off and S2 is still turned on. The current flow path is shown in Figure (d). The DC source, Lm and Lk1 are connected in series to transfer their energies to Lk2, C1 and the load. Thus, iLm and iLk1 are decreased and iLk2 is increased. Meanwhile, the energy which is stored in Lk1 is recycled to $\mathrm{C} 1$ and the load. The energy which is stored in C2 is still discharged to the load. This mode ends when iLk1 is equal to iLk2 at $\mathrm{t}=\mathrm{t} 4$.

\subsection{Mode 5 [t4, t5]:}

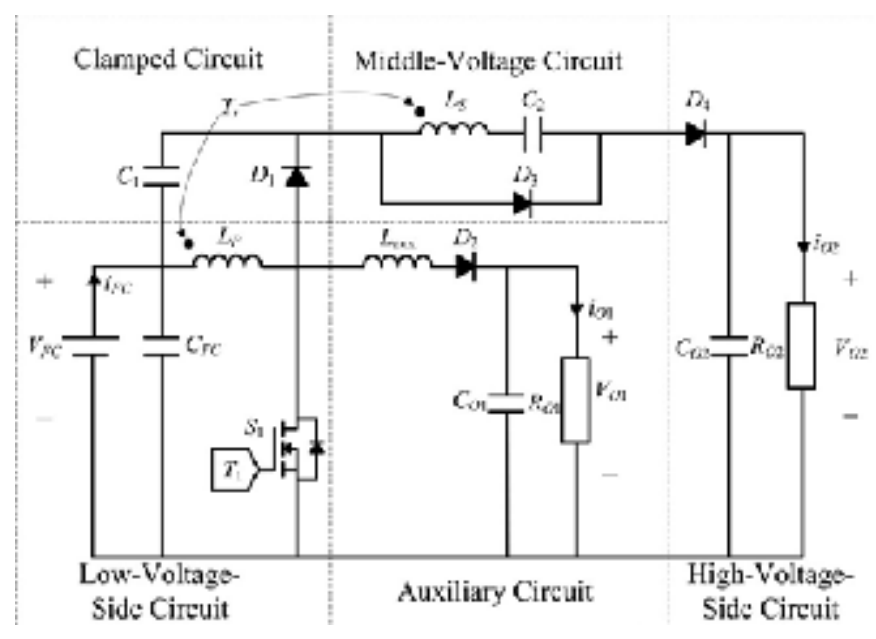

Figure 8 Mode 5

During this period, S1 is still turned off and S2 is still turned on. The current flow path is shown in Figure (e). The DC source, Lm, Lk1 and Lk2 are connected in series to transfer their energies to C1 and the load. Thus, iLm, iLk1 and iLk2 are decreased. The energy which is stored in C2 is still discharged to the load. 
3.6. Mode $6[t 5, t 6]$ :

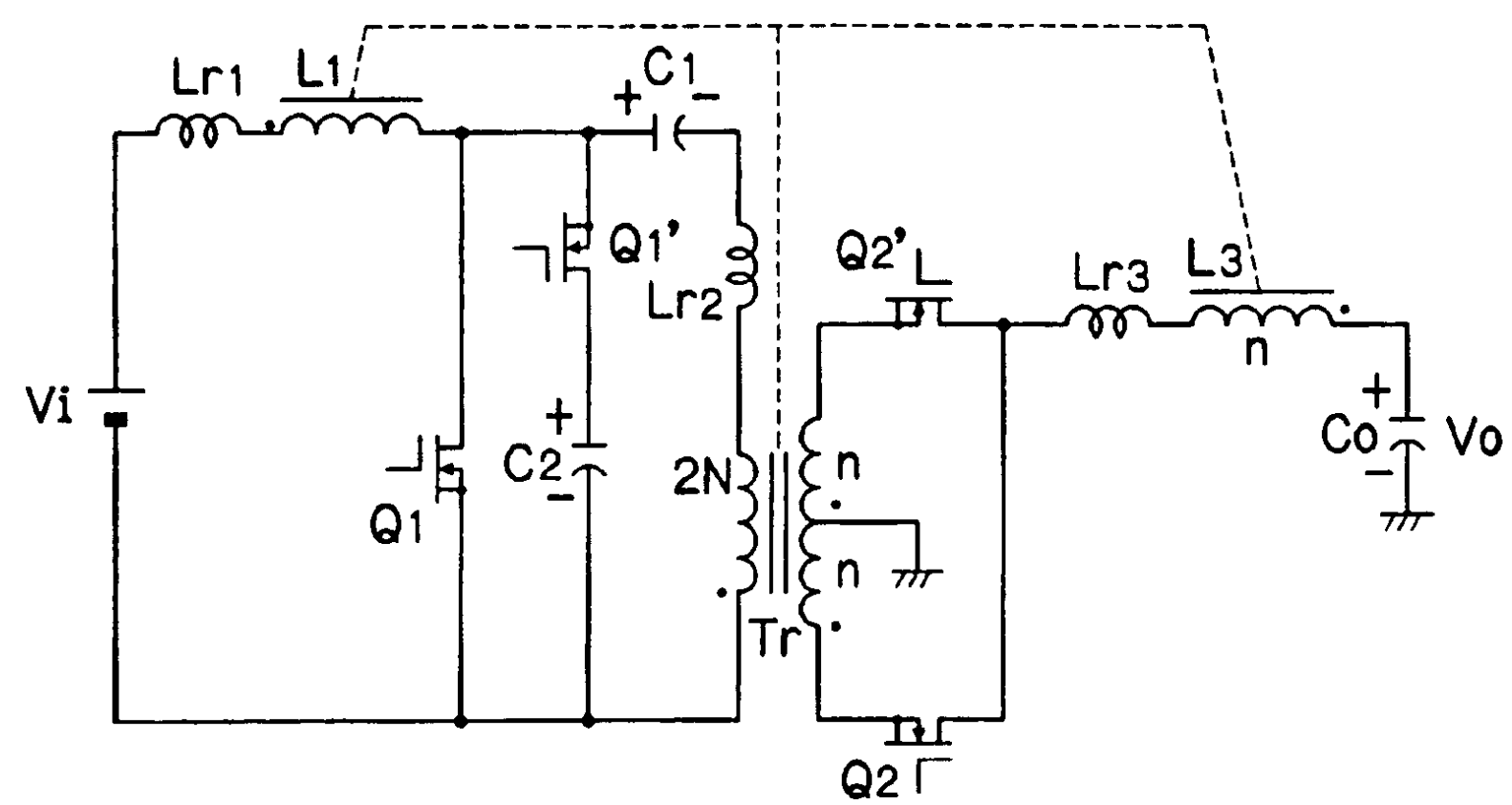

Figure 9 Mode 6

At $\mathrm{t}=\mathrm{t} 5, \mathrm{~S} 1$ and $\mathrm{S} 2$ are turned on. The current flow path is shown in Figure (f). The DC source energy is transferred to Lm and Lk1 through D3, S1 and S2. So, the currents iLm, iLk1 and iD3 are increased. The energy which is stored in Lk2 is released to $\mathrm{Lm}$ and Lk1 through D4, S1 and S2. Thus, iLk2 is decreased. Meanwhile, the energy which is stored in Lk2 is recycled. The energy which is stored in CS1 is rapidly and completely discharged. The energies which are stored in $\mathrm{C} 1$ and $\mathrm{C} 2$ are discharged to the load. This mode ends when iLk2 is equal to zero at $\mathrm{t}=\mathrm{t} 6$.

3.7. Mode 7 [t6, t7]:

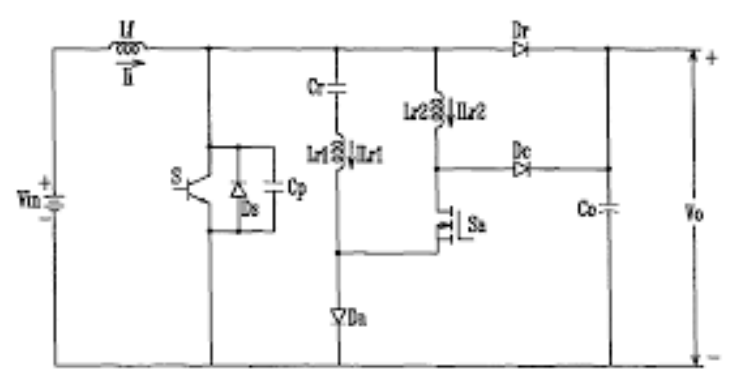

Figure 10 Mode 7

During this time interval, S1 and S2 are still turned on. The current flow path is shown in Figure (g). The DC source energy is still transferred to Lm and Lk1. Thus, iLm and iLk1 are still increased. The energies which are stored in $\mathrm{C} 1$ and $\mathrm{C} 2$ are still discharged to the load. 
3.8. Mode 8 [t7, t8]:

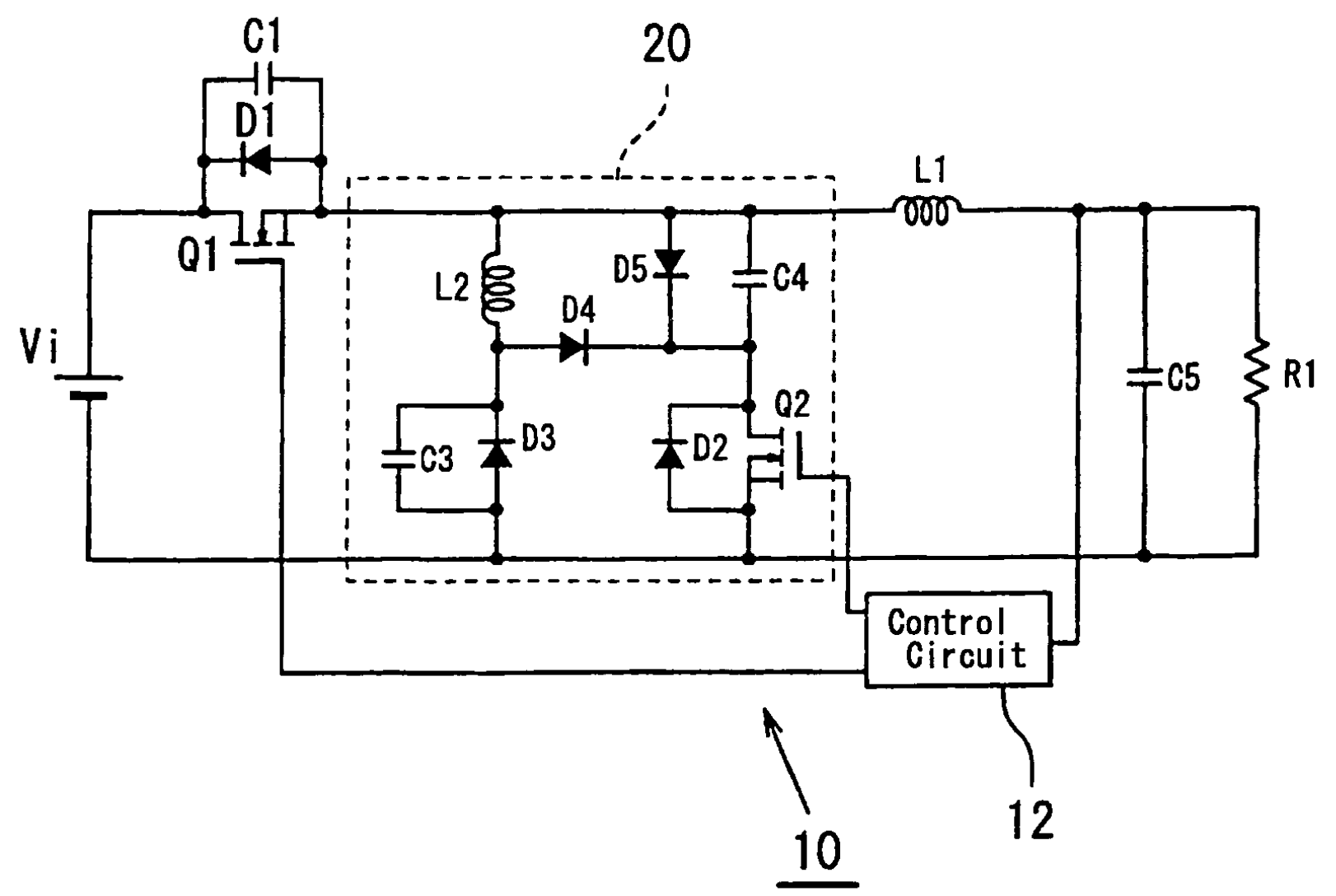

Figure 11 Mode 8

At $\mathrm{t}=\mathrm{t} 7, \mathrm{~S} 1$ is still turned on and $\mathrm{S} 2$ is turned off. The current flow path is shown in Figure (h). The DC source is still transferred to Lm, Lk1 and CS2. Meanwhile, the voltage across S2 is increased rapidly. The energies which are stored in $\mathrm{C} 1$ and $\mathrm{C} 2$ are still discharged to the load. 
3.9. Mode 9 [t8, t9]:

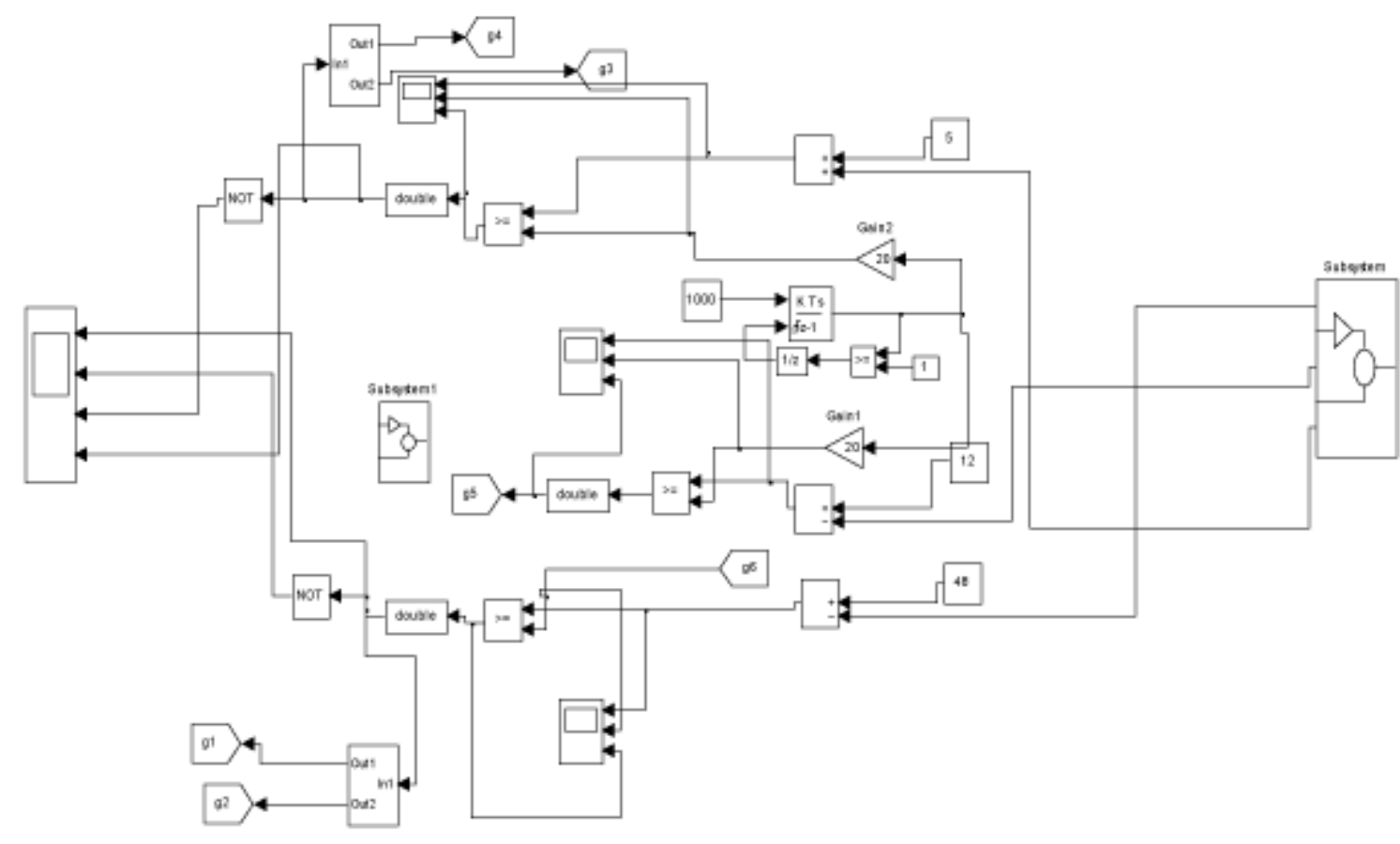

Figure 12 Mode 9

During this period, S1 is still turned on and S2 is still turned off. The current flow path is shown in Figure (i). The DC source, Lm and Lk1 are connected in series to transfer their energies to Lk2, C2 and the load. Thus, iLm and iLk1 are decreased and iLk2 is increased. Meanwhile, the energy which is stored in Lk1 is recycled to C2 and the load. The energy which is stored in C1 is still discharged to the load. This mode ends when iLk1 is equal to iLk2 at $\mathrm{t}=\mathrm{t}$.

3.10. Mode 10 [t9, t10]:

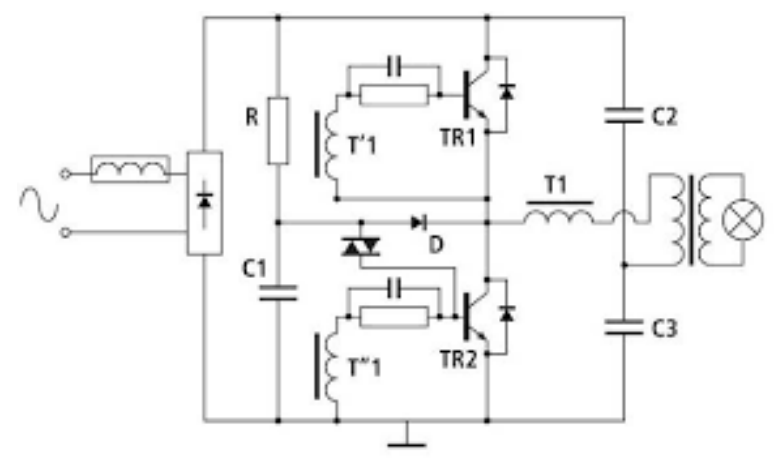

Figure 13 Mode 10

In this mode, S1 is still turned on and S2 is still turned off. The current flow path is shown in Figure (j). The DC source, Lm, Lk1 and Lk2 are connected in series to transfer their energies to C2 and the load. Thus, iLm, iLk1 and iLk2 are decreased. The energy which is stored in C1 is still discharged to the load. This mode ends when S1 and S2 are turned on at the beginning of the next switching period. 


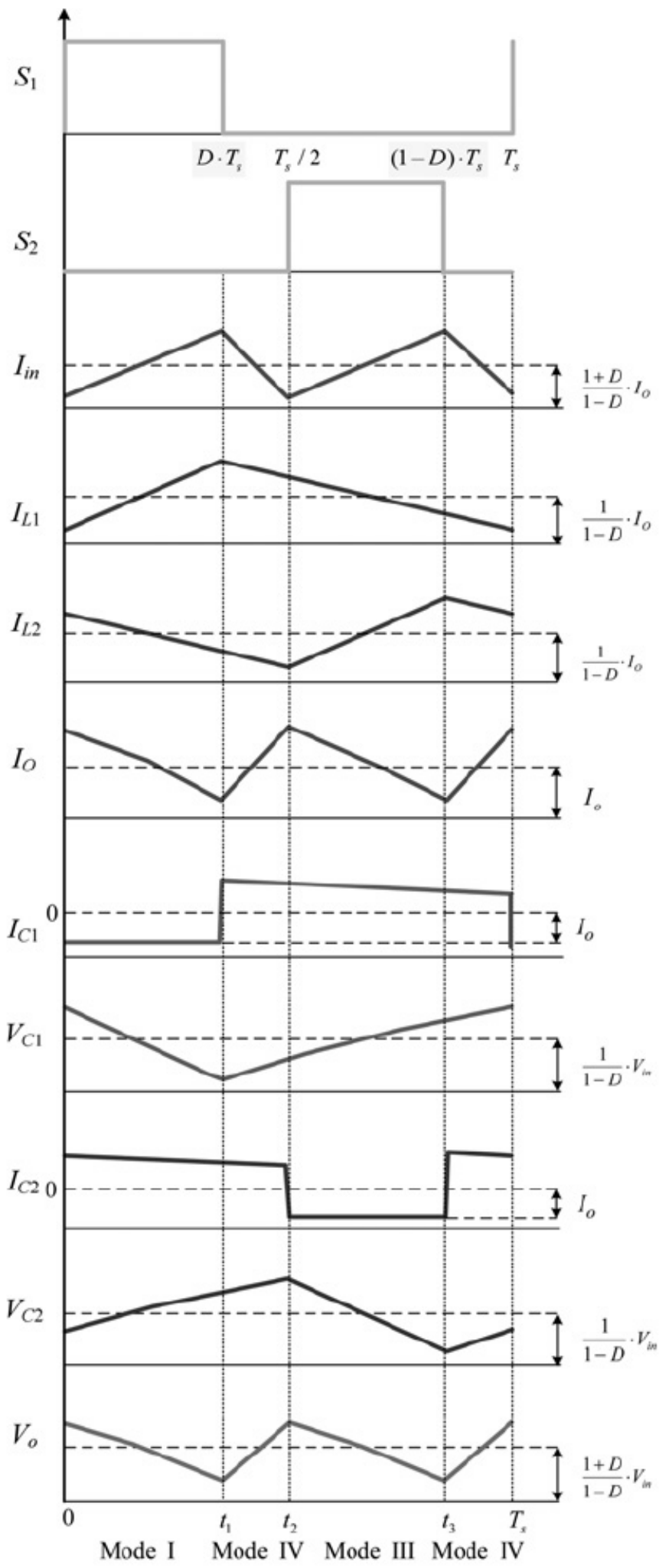

a

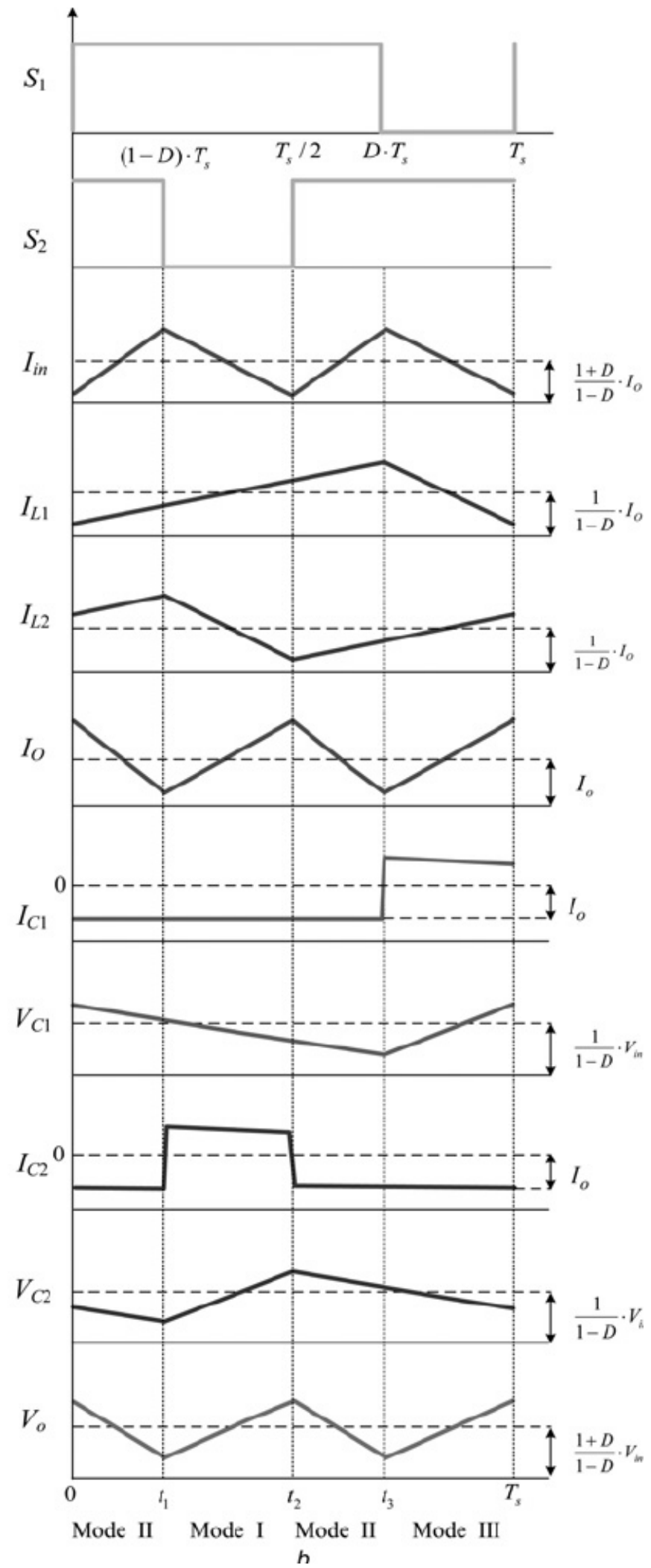

h

Figure 14 Typical Waveforms of the Proposed High Step up DC DC Converter 


\section{Simulation Circuit:}

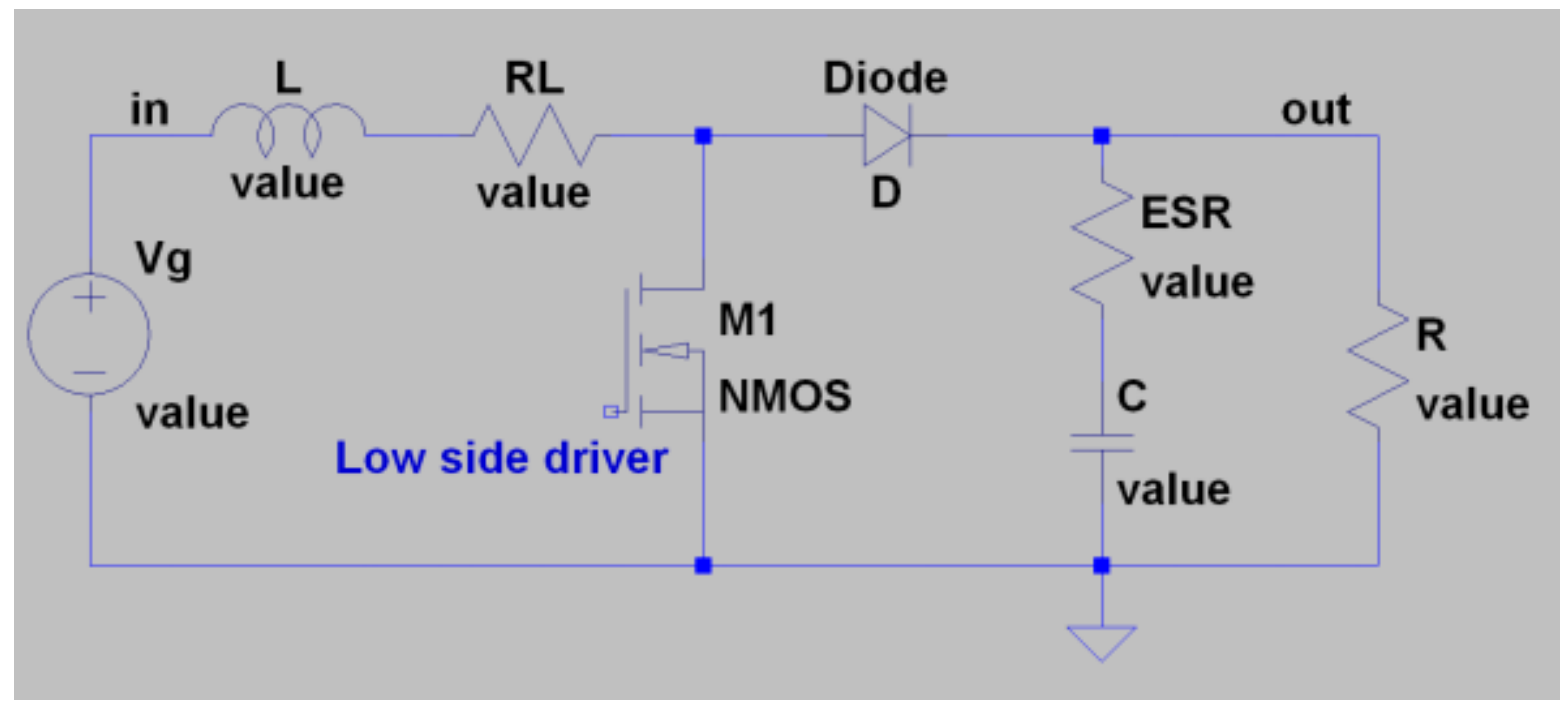

Figure 15 MATLAB Simulated Circuit for the Open Lop Circuit of the Proposed High Step up DC DC Converter

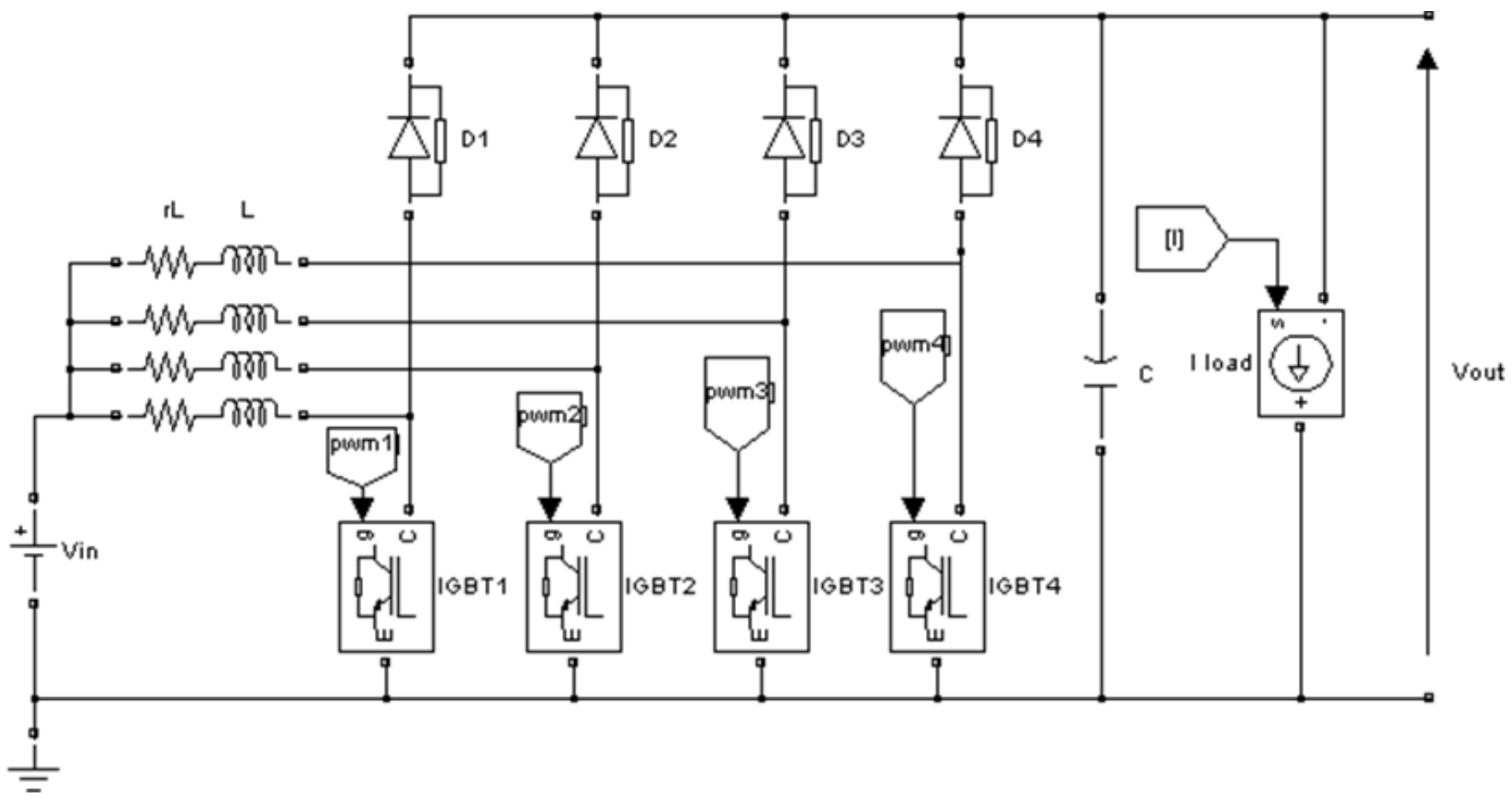

Figure 16 MATLAB Simulated Circuit for the Closed Loop Circuit of the Proposed High Step up DC DC Converter 


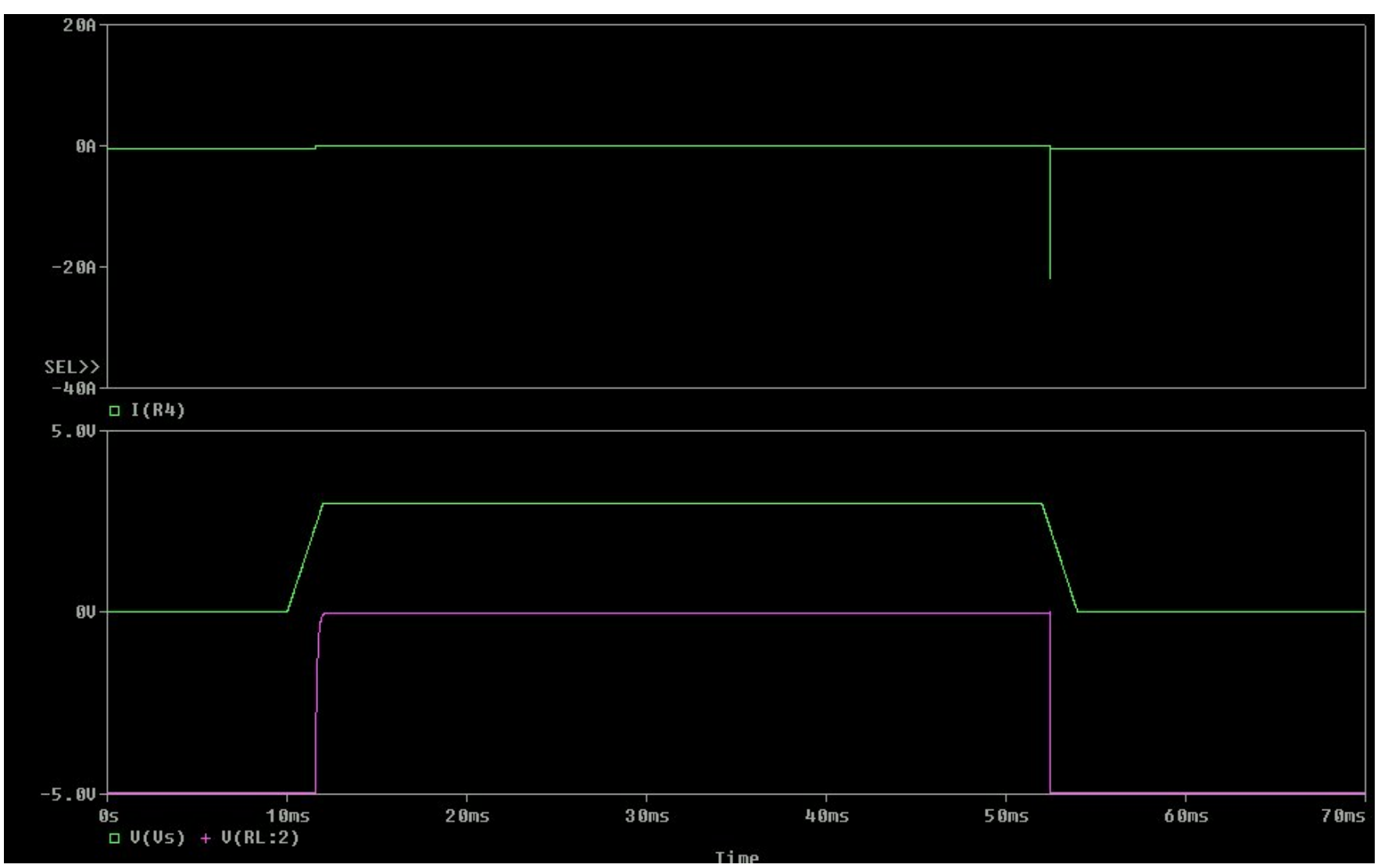

Figure 17 Gate Pulses of Switches

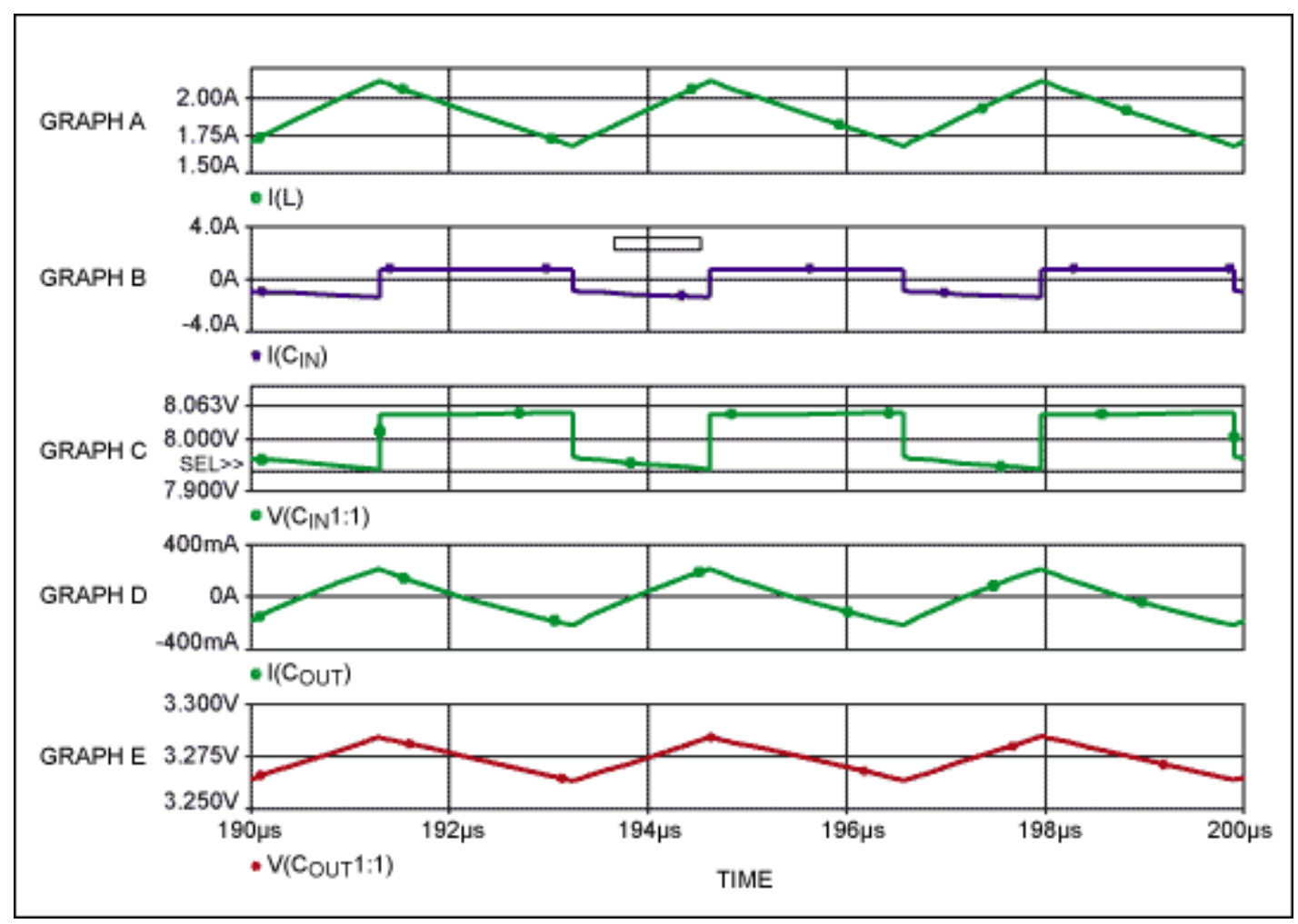

Figure 18 Voltage and Current Waveforms of Switch 

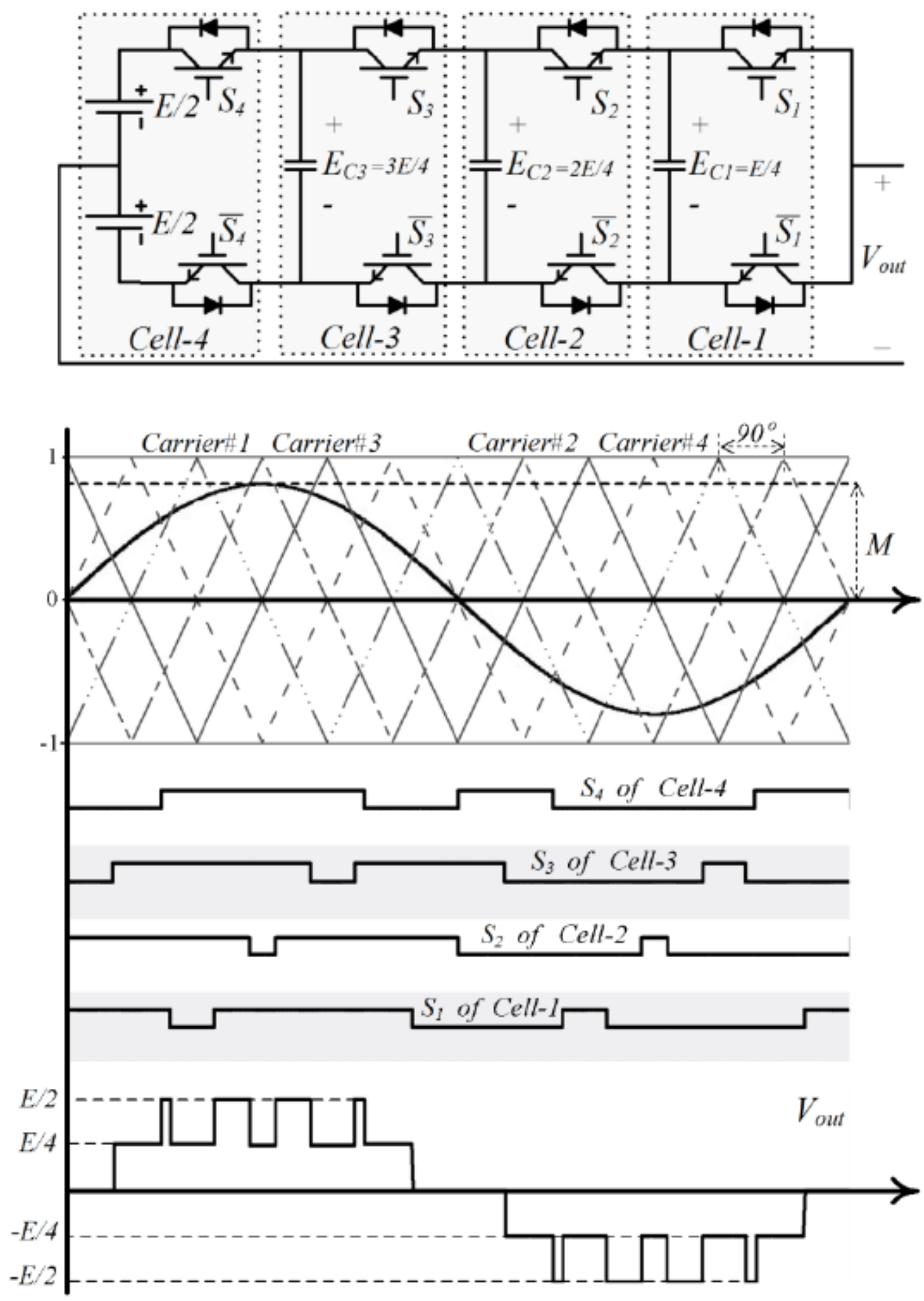

Figure 19 Output Voltage Waveforms of the Proposed High Step DC DC Converter 


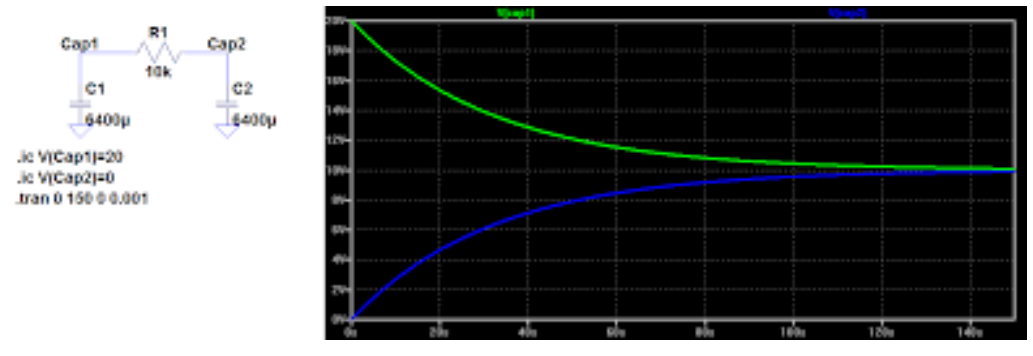

Figure 20 Voltages across Capacitors $\mathrm{C} 1$ and $\mathrm{C2}$

\section{Applications:}

The DC-DC converter with a high step up voltage gain is widely used for many applications, such as fuel cell energy conversion systems, solar cell energy conversion systems and high intensity discharge lamp ballasts for automobile head lamps. In the recent years, more and more industrial applications have required DC-DC converters which are able to provide a large conversion ratio with a good efficiency and less electromagnetic interference noise. Just a few examples show the need of a step up or step down of the input voltage of at least ten times: the 48 Volts nominal telecom DC bus has to be boosted at the intermediate 380 Volts DC bus which is needed for the supply system of the servers for the purpose of data processing when the telecom industry is sued to provide the computer services. The 12 Volts of a car's battery voltage has to be boosted up to 100 Volts during the steady state operation and even up to 400 Volts during the at the start up of the high Intensity discharge (HID) lamp ballasts which is used in the automotive head lamp.

\section{Advantages:}

[1] The leakage inductor energy of the coupled inductor can be recycled.

[2] The voltage stresses on the switches are half the level of the output voltage. Thus, the switches with a low voltage rating and a low ON state resistance RDS (ON) can be selected.

[3] The voltage gain which is achieved by the proposed converter is double that of the conventional high step up converter. Under the same voltage gain and the duty ratio, the turns ratio of the coupled inductor for the proposed converter can be designed to be less than the conventional high step up converter.

[4] The frequency of the magnetizing inductor current for the proposed converter is doubles that of the switching frequency. Thus, the magnetizing inductance of the coupled inductor for the proposed converter can be designed to be less than the conventional high step up converter under the same switching frequency.

\section{Conclusion:}

The novel high boost converter by using the coupled inductor and the voltage doubler was presented and the operation and the features have been described. The experimental results were discussed with a 200 Watts prototype by using the voltage doublers. The proposed method eliminates the problems of extreme duty ratio or the complexity of the circuits in the conventional topology. Also, the proposed circuit has the following various advantages as compared to the conventional booster converters: low voltage stress, higher boost rate, higher efficiency and several modified circuits for other applications. Therefore, the proposed converter can be applied to the various high boost applications, such as a battery backup system, fuel cells, military applications etc. 


\section{References:}

[1] Lung-Sheng Yang, Tsorng-Juu Liang, Member, IEEE, Hau-Cheng Lee and Jiann-Fuh Chen, "Novel High Step-Up DC-DC Converter with Coupled Inductor and Voltage Doubler Circuits", International Journal of Science, Technology and Engineering (IJSTE), Volume 5, Issue 6, May 2012, pp. 45-56.

[2] B. Axelrod, Y. Berkovich and A. Ioinovici, "Switched Coupled Inductor Ceil for DC-DC Converters with Very Large Conversion Ratio", International Journal of Engineering, Science and Technology (IJEST), Volume 5, Issue 8, August 2011, pp. 34-42.

[3] K. B. Park, H. W. Seong, H. S. Kim, G. W. Moon and M.J. Youn, "Integrated Boost Spice Converter for High Step-Up Applications", International Journal of Electronics Engineering, Computer Science and Information Technology (IJEECSIT), Volume 5, Issue 6, June 2014, pp. 34-45.

[4] R. J. Wai and R. Y. Duan, "High Step-Up Converter with Coupled Inductor", International Journal of Computer Science and Artificial Intelligence (IJCSAI), Volume 4, Issue 3, March 2014, pp. 28-35.

[5] J. W. Baek, M. H. Ryoo, T. J. Kim, D. W. Yoo and J. S. Kim, "High Boost Converter Using Voltage Multiplier”, International Journal of Computer Graphics and Pattern Recognition (IJCGPR), Volume 5, Issue 4, April 2013, pp. 28-38.

[6] R. J. Wai, C. Y. Lin, R. Y. Duan and Y. R. Chang, "High Efficiency DC-DC Converter with High Voltage Gain and Reduced Switch Stress", International Journal of Computer Science Engineering (IJCSE), Volume 5, Issue 6, June 2014, pp. 35-44.

[7] Q. Zhao and F. C. Lee, "High Efficiency, High Step-Up DC-DC Converters", IEEE Transactions on Power Electronics, Volume 32, No. 23, July 2012, pp. 2308-2313.

[8] K. C. Tseng and T. J. Liang, "Novel High Efficiency Step Up Converter", Proceedings of Industrial Electronics Engineering and Electrical Power Applications, Volume 151, No. 2, March 2004, pp. 182190.

[9] T. J. Liang and K. C. Tseng, "Analysis of Integrated Boost Fly back Step Up Converter", Proceedings of the Industrial Electronics Engineering-Electrical Power Applications, Proceedings of Industrial Electronics Engineering-Electronics Power Applications, Volume 152, No. 2, March 2005, pp. 217-225.

[10] R. J. Wai, C. Y. Lin, R. Y. Duan and Y. R. Chang, "High Efficiency DC-DC Converter with High Voltage Gain and Reduced Switch Stress", IEEE Transactions on Industrial Electronics, Volume 54, No. 1, February 2007, pp. 354-364. 